This is the author's final, peer-reviewed manuscript as accepted for publication. The publisher-formatted version may be available through the publisher's web site or your institution's library.

\title{
Making a difference in making miracles: common roadblocks to miracle question effectiveness
}

Sandra M. Stith, Marjorie L. Strachman Miller, Jeremy Boyle, Jonathan Swinton, Gary Cole Ratcliffe, Eric E. McCollum

\section{How to cite this manuscript}

If you make reference to this version of the manuscript, use the following information:

Stith, S. M., Miller, M. L. S., Boyle, J., Swinton, J., Ratcliffe, G. C., \& McCollum, E. E. (2012). Making a difference in making miracles: Common roadblocks to miracle question effectiveness. Retrieved from http://krex.ksu.edu

\section{Published Version Information}

Citation: Stith, S. M., Miller, M. S., Boyle, J., Swinton, J., Ratcliffe, G., \& McCollum, E. (2012). Making a difference in making miracles: Common roadblocks to miracle question effectiveness. Journal of Marital and Family Therapy, 38(2), 380-393.

Copyright: (c) 2010 American Association for Marriage and Family Therapy

Digital Object Identifier (DOI): doi:10.1111/j.1752-0606.2010.00207.x

Publisher's Link: http://onlinelibrary.wiley.com/doi/10.1111/j.17520606.2010.00207.x/abstract

This item was retrieved from the K-State Research Exchange (K-REx), the institutional repository of Kansas State University. K-REx is available at http://krex.ksu.edu 
Making a Difference in Making Miracles: Common Roadblocks to Miracle Question Effectiveness

Sandra M. Stith, Ph.D., Marjorie L. Strachman Miller, M.S., Jeremy Boyle, M.S., Jonathan Swinton, M.S., Gary

Cole Ratcliffe B.S., Kansas State University

Eric E. McCollum, Virginia Tech

Journal of Marriage and Family Therapy (in press) 


\title{
Making a Difference in Making Miracles: Common Roadblocks to Miracle Question Effectiveness
}

\author{
"Let me ask you a strange question. Suppose tonight while \\ you are sleeping, a miracle happens and the problems that \\ brought you to therapy are solved. You are asleep so, of \\ course, you don't know the miracle has happened. When \\ you woke up the next morning, what would be the first thing \\ that would tell you a miracle had occurred?”
}

\section{INTRODUCTION}

The miracle question is a foundational Solution-Focused Brief Therapy (SFBT) intervention that was created by Insoo Kim Berg (De Jong \& Berg, 2002). One day a client, who seemed completely unable to envision any difference in her future, told Insoo "Maybe only a miracle will help.” Insoo explored this idea further with the client and Steve de Shazer (1988), who observed the session, was struck by the power of this question to lift clients out of the seeming constraints of "real life." After the session, they went on to develop and formalize the miracle question. The miracle question is usually asked early in therapy to create concrete therapeutic goals (de Shazer, 1988; De Jong \& Berg, 2002). In addition to lifting clients out of their constraint saturated view that nothing can change, the miracle question also helps them develop a specific and elaborated vision of what their lives would be like in the absence of the problem by asking them to imagine the minute and day-to-day details that would let them know that change has occurred in their lives. In addition to goal setting, three other reasons for asking 
the miracle question exist (de Shazer, Dolan, Korman, McCollum, Trepper, \& Berg, 2007). The first is to create a virtual experience of what life would be like if the miracle occurred. Another is to prepare clients to recognize exceptions to the problem, thereby demonstrating that the problem is not always present (de Shazer, 1988). Finally, the miracle question helps to create a progressive story, in which the client's life is seen as becoming better instead of worse. As Nau and Shilts see it, "The "miracle" clients are asked to envision is not just a wish. Rather, for the client and therapist, it may be the common ground upon which the two agree to build new foundations” (2000, p. 135).

Despite its seeming simplicity, asking the miracle question effectively can pose problems for therapists. Our experience is that students learning to use the miracle question often have problems making the question interactional when asking the question to couples and families and have problems knowing how to expand the question to allow clients to create a vision of a life after the miracle. Although several SFBT therapists have written about how to effectively use the miracle question in session (de Shazer et al., 2007; De Jong \& Berg, 2002; Nau \& Shilts, 2000; Shilts et al., 2003), no one has examined challenges that student therapists face when learning to use the question. While pointing out problems creates a dilemma from a solutionfocused perspective, we have found that when students are able to recognize pitfalls, it is easier for them to avoid them in the future. This paper highlights these pitfalls so that students can learn to avoid the challenges and ask well-timed and well-phrased miracle questions.

The common guidelines for effective use of the miracle question include phrasing the question correctly, creating goals, joining, actively looking for exceptions to the problem, being patient, using pauses, remaining future oriented, and responding to clients constructively. Peter De Jong and Insoo Kim Berg (2002) also suggest that the effectiveness of the miracle question 
depends on the therapist's ability to maintain a duality of appearing relaxed and yet being controlled and completely aware of the client. Specific guidelines are provided about the delivery of the miracle question, including speaking slowly and gently, pausing, and using a future focus. Furthermore, an SFBT stance of believing that the clients have the competence to make their lives better is required of the therapist.

The most recent description of the use of the miracle question is included in two chapters of de Shazer and colleagues' book More Than Miracles: The State of the Art of Solution-Focused Brief Therapy (2007). Here, the authors explain that "ultimately the miracle question is not so much about figuring out what would be a "dream come true" miracle for this person or family as it is about discovering, identifying, and replicating the tangible, observable effects of it” (p. 40). Thus, it is important for the therapist to follow the lead of the client, be collaborative, and actively seek the nuances of the description of the solution rather than accept grand answers such as 'I would win the lottery.'

de Shazer and colleagues go beyond phrasing the miracle question as a single question and provide a detailed description of how to ask it as part of a larger process of developing a future vision of life without the problem and starting to chart the course toward realizing that future (2007, pp. 42-43). They also suggest that asking the miracle question and developing a strong and workable vision of the future will usually take the entire session. The intent behind each step of the miracle question process, as well as how to deal with various responses from clients, is described. The therapist starts by anchoring the miracle question in the client's everyday life, adding details to the narrative of the question that makes it specific to that client (“Suppose when you go to sleep tonight, when you are in your own bed, and your children Maria and Antonio are asleep, and after you have taken care of your evening chores ...”). The miracle 
question is then asked and the therapist waits for the client to absorb the question and formulate a response. As the client begins to describe what will tell them that a change has occurred, the therapist prompts them for specific and behavioral details (Client: "I'd be happy.” Therapist: “What would you see yourself doing that would tell you that you were happy?”) The follow up questions then become reflexive, weaving the evidence of the miracles into the client's network of interpersonal relationships ("How would your husband know that you were happy? What would he see?") Further reflexive questions begin to turn the focus toward the future ("If your husband saw you smile at him and he knew that meant you were happy, how might he respond to you?") After some period of elaboration, the process is anchored in a scaling question that further points the way to the future (Therapist: "So, on a scale of 0 to 10 where 0 is where you were the day you made the call to come to therapy and 10 is the morning after the miracle, where would you put yourself now?” Client: "I don’t know ... maybe a 4.” Therapist: "What will tell you when you have moved ahead a little bit, say to a 4 and a half?”) This scaling question sets the stage for subsequent sessions which can begin with a discussion of what has gone well since the last session and where the clients sees themselves on the scale at present. Clearly, negotiating the miracle question process with a client so that they can suspend disbelief and enter into the imagined world after the miracle takes skill and is fraught with potential pitfalls. While several SFBT therapists describe the skills needed, fewer have mapped the pitfalls. As stated above, the purpose of this paper is to learn from some of the mistakes that students learning to use the miracle question make in delivering the intervention most effectively to improve teaching and learning how to use the miracle question Although our approach to supervising students is generally to highlight successful interventions and to point out what students are doing well, for the purpose of this project we selected examples from students' work that 
highlighted ineffective use of the miracle question so that we could help them and others learn to avoid these roadblocks.

\section{METHODS}

Data used for this project came from videotapes of first interviews created by six therapists-in-training (one tape for each therapist-in-training) at an accredited marriage and family therapy master's program. The student therapists ranged in age from 23 to 35 . Four were women and two were men. In this paper, we call the female therapists "Mary", "Pam”, "Sue”, and "Angela" and the male therapists "John" and "Peter." The student-therapists had completed two semesters of training in most models of family therapy in their marriage and family therapy theory courses. Their course included an overview of SFBT and had learned how to use the miracle question in one class period. They had not begun to see clients, but had chosen to use the question in a final class project, a videotaped role-play first interview. The role-play clients were students from the same cohort, who received the same coursework as their counterparts. Students were not required to use the miracle question, but many of them thought it would be helpful. Since the problems that got in the way of the student-therapists' effective use of the miracle question in their role plays were consistent with the problems the instructor had noted when observing beginning therapists behind the one-way-mirror with actual clients, she asked the student-therapists for signed permission to use transcripts of their first interview tapes in this project.

Research Team

A research team coded and analyzed the tapes. The research team began meeting after the student-therapists graduated, therefore none of the student therapists were on the research team. 
The research team included the faculty member who collected the data, three male and one female graduate student. Three of the five team members were doctoral students, one was a master's student, and one was a professor. Each of the research team members had training in SFBT. In addition, as described below they prepared for coding the tapes by reviewing pivotal work in SFBT. Four of the five team members had completed coursework and had experience coding and analyzing qualitative data. The student members of the team were under the age of 30. The tapes were transcribed before the team began meeting, therefore student team members did not know the identity of the student-therapists. The sixth author of the paper is a professor in a different university and was not a member of the research team. He is an experienced SFBT trainer.

Analysis

Qualitative analyses of the role-play videotapes were based on thematic analysis, a method for identifying, analyzing, and reporting patterns (themes) within data (Braun \& Clarke, 2006). To be considered a theme, a roadblock or example of an ineffective use of the miracle question had to have occurred more than once and had to represent what the team members believed was a key roadblock to effective use of the miracle question.

The steps in the data analysis procedure were as follows (Maxwell, 1996; Tesch, 1990):

1. Each tape was transcribed verbatim.

2. The team prepared for analyzing the transcripts by reading important publications on the use of the miracle question including the chapter “The Miracle Question,” in More than Miracles: The State of the Art in Solution-Focused Brief Therapy (de Shazer et al., 2007), and the chapter entitled “How to Amplify What Clients Want: The Miracle Question” in the book, Interviewing for Solutions: Second Edition (De Jong \& Berg, 2002) and by 
viewing a video of the sixth author of this paper using the miracle question with a couple in session. From this preparation, team members developed sensitizing concepts.

3. In order to get a sense of the whole, each team member read through each transcript in its entirety and initial, tentative notes about potential categories and themes representing ineffective use of the miracle question were recorded.

4. As a group, the team read each transcript line by line. Team members discussed the themes and sub-categories they had noted in the transcripts and a master list of themes and subcategories was developed. Similar ideas were clustered under the same theme and sub-categories within each theme were developed. These clustered themes were abbreviated as codes.

5. The data were revisited (each transcript was read again) and the developed codes were applied to the appropriate segments of the text.

6. Coded data for each theme and sub-category were extracted from original transcripts and a new document was developed that displayed all coded data together, by theme/subcategory.

7. The data were re-examined, looking for additional themes. In addition, salient quotes were highlighted that seemed to be representative of the various themes and subcategories to be used in the dissemination of the findings.

When conflicts existed between team members regarding whether the section of transcript represented an ineffective use of the miracle question, the team went back to the literature and came to group consensus. Through this iterative process of "taking apart" the data and seeking commonalities as well as exceptions, three general themes emerged to represent roadblocks to effective use of the miracle question. Finally, an experienced SFBT practitioner 
and trainer (the sixth author of this paper) reviewed the paper and provided expert validation of the pitfalls identified by the research team.

\section{RESULTS AND DISCUSSION}

Three themes emerged from the data. The first broad theme included problems related to how the miracle question was introduced. The primary subcategories that emerged in this theme were poor transitioning from the content addressed earlier in the session into the miracle question and poor timing within the session. The second broad theme included problems related to framing of the miracle question. Subcategories that emerged from this theme included: therapistled versus client-driven miracle definition and asking the question in a confusing way. The final theme involved the way the student-therapists followed up on the miracle question. The four specific subcategories included lack of commitment to the question (e.g., jumping right into goal setting or problem solving without trusting the process of the miracle question), focusing on the elimination of negative behavior or on changes other people will make rather than on changes made by the client, not making the question interactional, and finally, not using scaling questions effectively after the miracle is described.

Introduction of the miracle question

The first broad roadblock to effective use of the miracle question involved the way the miracle question was introduced. The primary problems which were included as subcategories to introduction of the miracle question were poor transitioning from the content addressed earlier in the session into the miracle question and insufficient allocation of time to the miracle question within the session.

Abrupt or no transition from previous conversation. The primary subcategory that emerged in this theme was that all of the therapists-in-training tended to introduce the miracle 
question abruptly with little or no transition from the previous conversation and/or at the end of the session when there was no time to follow up the question. While most beginning therapists tend to be anxious when they start practicing therapeutic skills, we noticed that the studenttherapists seemed to use the miracle question to relieve the anxiety that was produced during the session, regardless of what the client had just said or how little time was left in the session. It appeared as though, at times, the therapists asked the miracle question as a way to change the subject when they seemed stuck. Another possibility was that the therapists may have also been unsure about the appropriate time to ask the miracle question, so they were anxious about applying the skill correctly.

The tone used when asking the miracle question is crucial to delivering it effectively (de Shazer et al., 2007; Shilts et al., 2003). de Shazer and colleagues (2007) believe that the miracle question is delivered effectively when a therapist appears relaxed but still focused on the client at all times. The therapist should create a hypnotic state because "for many people, the activity of answering appears to elicit a significant shift in their state of consciousness" (de Shazer et al., 2007, p.42). The clients should reach a calm state in which they are open to answer the miracle question. Thus, it is important for therapists-in-training to learn how to utilize this technique comfortably. Nau and Shilts (2000) found that four of the most prominent solution-focused therapists delivered the miracle question only after solidly joining and deeply understanding the presenting problem.

In our sample, however, therapists-in-training tended to use abrupt transitions into the miracle question. They frequently began the miracle question when the clients' conversation became repetitive and problem-focused. Because the student-therapists were not interviewed, it was not possible to know what they were thinking when they asked the miracle question. 
However, it seemed that the therapist used the miracle question when he or she didn't know what else to do. For example, in one session a father and daughter argued about her parents monitoring her activities, and the therapist immediately asked the miracle question without any transition from the problem that the clients were addressing.

Daughter: They call me on it every ten minutes if I'm not at home.

Father: It's not every ten minutes

Daughter: Okay fifteen!

Mary: Okay let's do some focusing on some of the cycling we're seeing here, and maybe how things could be different. Because I happened to have a chance to talk to Tim [father], you, earlier and Laura [daughter] just listening to you...I'm going to ask for you guys to kind of umm, I guess be patient with me because I'm going to ask you all to participate in something that's a little kind off the cuff, a little different, ummm, but it's going to be helpful for me to try and gauge kind of what's going on. Ummm, and to kind of see where you, where you want to be. Umm it's becoming more apparent, kind of, where you are and where you both, you all are feeling stuck. Umm, so, umm, So is that something that you guys are willing to do? It's a little exercise I want to take you through with me.

At this point, Mary asks the miracle question. This quote illustrated several of the problems we identified in this study, but what stood out for us here was the lack of a noticeable transition from the father-daughter argument to the miracle question. Although the family agreed to participate in the miracle question, the daughter responded to Mary's miracle question by listing behaviors that her father would not do, at which point the therapist switched the focus to her mother. It is possible that if Mary had been able to create a hypnotic state instead of 
abruptly transitioning from an argument to the miracle question, the daughter might have been more able to vision a future after the problem is resolved.

Furthermore, four of the six therapists-in-training began the miracle question with the word "okay." Using this word seemed to announce that the therapist was switching gears, which would be more likely to jolt the clients than to shift their consciousness into a hypnotic state.

Timing of asking the miracle question. Another key ingredient to the miracle question is timing. In order for the miracle question to be asked effectively, it needs to be asked with enough time remaining in the session to accomplish the goals of the miracle question. It was clear from the transcripts that two of the six therapists did not leave enough time for the miracle question to develop. For example, one student-therapist, Sue, asked the question towards the end of the session when things were not going well.

Wife: Before Tim [the baby] came we were on the same wave length and then Tim came and it just changed everything you know... It's like we just don't get each other now. And we just don't know how to get each other. . It's just hard and you know? It's not that easy anymore.

It was clear at this point that the client was feeling distraught and desired to have some validation of how hard her life is. However, this is not what the client gets from Sue. As in the examples above, Sue transitioned into the miracle question with no attention to the ongoing conversation:

Sue: Okay. I'm going to ask both of you a very strange, strange, weird question.... Sue continues with the miracle question dismissing everything the client has just expressed. Perhaps Sue had decided at the beginning of the session that she was going to ask the miracle question and was afraid that if she focused on validating the concerns of the wife she 
would not have enough time to ask the miracle question. Sue's actions in this session go against an important timing issue of asking the miracle question, which is to understand the depth of the presenting problem before asking the miracle question (Nau \& Shilts, 2000).

In another session, John also timed the usage of the miracle question at the end of the session:

John: Well let's try that. Let's see if that will work. If that's something that we can work on, to see if we can get everybody...

Wife: To be in the same room (laughs).

John: (Laughs) Yeah definitely. I mean we could have ...Maybe she could come in next week and we could just work the three, the four of us together and then maybe the children a week or two after. Um how does that sound to you guys?

Husband and wife: Sounds good

Wife: We could do that.

The therapist has just talked with the client about plans for future sessions and it appears that the session should be wrapping up. Instead of ending the session, however, John, probably unaware of the time, continues the session by saying:

John: Okay. Well, Um, I feel, I think I've got a good picture here. I want to throw out a question here for you guys. Um it might seem a little out there but I think it's good to think about...

John continues by asking the miracle question and the wife responds to his question. After the wife responds to the miracle question in one sentence, John leaves the miracle question by focusing on problem solving, which is another pitfall that will be discussed in this paper. After 
discussing how to solve the problem for a very brief period of time, John ends the session by saying,

John: Okay. Um, we're almost done here. I just want to first get a feeling for where we're at right now. Um, on a scale of one to ten...

It was clear that John did not leave enough time to explore what the miracle might look like for the couple.

The amount of time we give to an intervention in therapy may indicate to the client the amount of importance that we place on the intervention. If a therapist only gives a few moments to the miracle question, the client may see that having the miracle happen may not be important. If the therapist gives more time to the miracle question, the client may sense the power that the question can have when given enough time and thought in therapy. Framing of the question

One subcategory that emerged in the second broad theme of "framing of the miracle question” included asking the question in such a way that the therapist anticipated or prescribed what the client's miracle would or should be. We labeled this sub-theme as "therapist-led versus client driven miracle.” The other subcategory in the framing of the question category was asking the question in a disjointed or confusing way which diluted the process of answering for the clients. This subcategory was labeled "confusing phrasing of the miracle question."

Therapist-led versus client-driven miracle. The first roadblock to the effective use of the miracle question related to framing the miracle question was the tendency of student-therapists to create the miracle for their clients rather than to allow the clients to create their own miracle. De Jong and Berg (2002) indicate that in solution-focused interviewing, which includes the miracle question, "the practitioner refrains from making suggestions to clients about what they need or 
for what they should strive” (p.84). They further explain that therapists should refrain from defining the miracle because as clients create their own goals, or own miracle, they brighten up and become more hopeful. In addition, clients are more likely to stay attentive to the process (p.90). We observed that most therapists-in-training in our sample did not refrain from sharing their own suggestions, and as a result clients lost their attention to the miracle, pursued the less hopeful course by discussing their problems, and were not likely to venture out from the therapist's miracle to share their own miracle. Consider the following interaction between Peter, the student-therapist, and client:

Peter: And the next morning you wake up and a miracle has occurred. And you don't know that it's happened, but all of the, all of the confusion, all of the difficulties that you've been having in coping with taking care of the baby, and trying to get a job, and get balanced like that umm, have been taken care of. And you are taking care of the baby, you are holding down a job and you're happy. Um what would, how would you know that that had occurred?

Daughter: I think...you know I think the biggest thing is that I do want to have a job. I just don't see how I can do it all...I think that I would like to have an apartment of my own and to have a job that I like and to be able to pay for everything. So..., but I feel like I can't.

The client quickly lost attention of the miracle and illustrated hopelessness by focusing on her problems. In addition, her employment was the only topic of discussion during the remainder of the dialogue. Perhaps if her employment was not suggested through Peter's miracle, other aspects of the client's miracle could have been discussed. The following is another example of a therapist-led miracle: 
Sue: ...And what has happened is that a miracle has occurred and all these problems have gone away. You all, you two are able to interact like you once did. You both, you don't have as many conflicts, you're able to talk to each other without screaming and yelling. That's the miracle, but you don't [know] what has happened. So what would be the first indication that this miracle has occurred to you?

In both examples, student-therapists seemed to not trust that clients could come up with the miracle that was most important to them and inadvertently blocked the client's effort to create their own miracle.

Confusing phrasing of the miracle question. The phrasing of the miracle question itself is crucial for it to be effective (de Shazer, 1988; de Shazer et al., 2007; De Jong \& Berg, 2002). The phrasing of the miracle question was confusing when student therapists asked the question in an awkward manner, asking unrelated questions back-to-back, and when the student-therapists seemed confused about what they were asking of the clients. De Jong and Berg (2002) maintain that while there are many ways to ask the miracle question, it is best asked deliberately and dramatically. Most of the beginning therapists tended to ask the question in a confusing, choppy way. After an awkward delivery of the miracle question, the miracle question tended to fall flat because clients seemed confused and did not know how to answer. While the miracle question can potentially be drawn out and multiple questions can be useful, the student therapists did not pick back up on the question, and the technique ended quickly.

Also, the process was clouded with double and multiple questions attached to the miracle question. "The practitioner's task is to pose a series of related questions to invite clients to express their vision of a more satisfying future in a manner that reflects these characteristics” (De Jong \& Berg, 2002, p. 86). In a recorded session that we viewed as part of this project, the 
sixth author of this paper, an experienced SFBT practitioner, led up to different parts of the miracle question by staying in conversation with his client couple. He gradually brought them into a deeper vision of their everyday routine. He then paused after saying that a miracle occurred and asked what the first thing that they would notice was, and redirected them to the first instant that they wake up. In contrast, the therapists-in-training in our sample asked the miracle question as one block of questions and left the clients open to respond to any one of them:

John: Well. Um, I feel, I think I've got a good picture here. I want to throw out a question here for you guys. Um, it might seem a little out there but I think it's good to think about. Um, I going to ask this to you Tammy (wife) and then we'll go back to Leonard (husband). I would like to know, let's say you go to sleep tonight after you leave the center, you go have dinner with your children you do whatever you do in a normal night. Um, you go to bed and you wake up the next morning and all the problems you came to see me here to talk to me about are magically gone. You know something happened over night and all these problems you came to talk to me about are just magically gone. So when you wake up in the morning what would show you that all those things were gone? As you go throughout your day from the time you wake up throughout the day what would show you that those problems are gone?

Wife: I think the first thing would be that I woke up a little later than usual. Because right now I have to wake up at 6 just to take care of everyone. And then have them all sent on their way...

John: Okay. Any other behaviors you notice? 
The client in this example elicits the first thing that happens when she wakes up, but John quickly moves on without gaining a better understanding of what the effects of sleeping later would be. Several of the clients' answers among the sample were not about the very first thing that they would notice when they awoke, such as a spouse cooking breakfast, being employed, or an exchange between family members. de Shazer et al. ( 2007) stress the importance of ensuring that clients have a clear mental image of their normal lives because this is where change occurs. The awkward way that the miracle question was asked by beginning therapists prohibited the clients from answering it with a picture of worthwhile changes in their everyday lives.

The relaxing atmosphere within the session that is usually created by the therapist which contributes to the effectiveness of the miracle question was blocked by the awkward, chunky, and abrupt phrasing by beginning therapists. We believe that most, if not all, clients have the potential to formulate goals with the presentation of the miracle question, but "beginners often...feel awkward asking the miracle question, even though clients may find it intriguing” (De Jong \& Berg, 2002, p. 101). The absence of the relaxed yet intentional demeanor of the therapist disconnects the clients from a hypnotic experience, and clients cannot become as involved in exploring solutions to their problems.

\section{Following up on the question}

Four subcategores emerged as problematic after the miracle question was asked, including lack of commitment to the question, not redirecting the client from a focus on the elimination of negative behavior or on changes other people should make to changes made by the client, not making the question interactional, and finally not using scaling questions effectively after the miracle is described. 
Lack of commitment. One of the most common problems that plagued all but one of the therapists-in-training in executing the miracle question was their lack of commitment to using the miracle question to its fullest potential. Therapists showed a lack of commitment to the miracle question by diverting away from the miracle prematurely. After asking the miracle question, student-therapists often did things such as abruptly shifting focus and ignoring the leverage that can be used based on the responses given when exploring the miracle.

Therapist trainees frequently shifted focus during the miracle. When one individual in the system offered a response to the miracle that the therapist thought could lead to problem solving, the trainees often left the miracle and went right to problem solving. For example, when seeing a mother and daughter, Peter, therapist-in-training, asked the dyad "how would you know that that [the miracle] had occurred? When the daughter says, "I think...you know I think the biggest thing is that I do want to have a job.” Peter seemed to seize this comment as a possible goal and seemed to move out of the miracle when he asks, "Since this miracle has already occurred what do you think you would be doing at this point"?

Daughter: You know I... for my job I think I'd like to work with people. I really like being with people and I think that I'd like to find something maybe where I work with people. Maybe I could work and do something outdoorsy like... a camp guide or something of some sort. Working with kids even that would be something fun I would like to do.

Peter: Okay. Um if you were taking a look at... would you be able to start looking for a position like that?

Peter then leaves the miracle and engages in a discussion about how the daughter could find the job. This clearly diverts the discussion far from the miracle into premature problem solving, 
preventing the daughter from exploring the benefits that could have been found in further exploration of her miracle.

In another case, Pam is only in the preliminary stages of discussing the miracle when she diverts from exploring the miracle by stating:

Pam: It's a big thing, to happen. Um, but it sounds like to me like both of you want something different out of your relationship. And I, and coming into therapy is a big step in that direction. And I want to congratulate you on coming in here, because it's a big thing.

Following this statement, the miracle is never discussed again in the session. The therapist-intraining appears to have only gone through the motions of exploring the client's miracle because nothing regarding what is brought up in the discussion is ever revisited. The therapist failed to explore the miracle further, help the couple understand how parts of the miracle are occurring already, and what small steps would have to occur to move one step closer (on a scale of 0 to 10) toward the miracle.

Focusing on the elimination of problematic behavior or on changes other people will make. Another theme that arose when therapists-in-training followed up on the miracle question was the tendency to not direct clients away from problems or other people. When clients are asked about a miracle in their lives, it is not uncommon for them to think of something changing outside of themselves. In fact, every therapist-in-training in our study experienced their clients talking about how someone or something outside of themselves would be different if a miracle happened. Our primary concern was not the clients' response to the therapist, but whether or not the therapist was able to redirect the clients back to themselves. For example, in the following 
dialogue the client mentions another person. Instead of redirecting the client, John, the therapistin-training, targets this as a topic of discussion.

John: ...what would show you that those problems are gone?

Wife: ... you know a couple times a week he takes over feeding them breakfast...

John: Okay. Any other behaviors you notice?

Wife: I'd be more relaxed, definitely more relaxed. Not having to worry about that I think, um, and knowing that there is someone else that's picking up, you know, it's still getting done. I've got to say that's pretty much it I guess.

John: I get the sense there is a lot of pressure on you.

Wife: Yeah

John: ...okay. So uh, do you think if he took more, you know took a little bit of that load off your shoulders...is that what you'd like to see?

Not only does John fail to redirect the client, he also began problem solving and the miracle question was lost. According to de Shazer et al. (2007, p.50), redirecting clients involves asking a "series of questions to clarify what the client would start doing then that he or she is not doing now and how other people would notice it.” In the following example, Mary is working with a mother and father and their daughter. She appears to be on the right track, asking a series of questions to lead the daughter back to herself, but suddenly jumps ship and leaves the daughter focusing on what her parents could do to fix the problems.

Mary: What do you notice that's different when you wake up?

Daughter: I wouldn't wake up to dad pounding on the door. Mary: Okay

Daughter: (in false father voice) Get up you got to get to school. 
Mary: Okay. What else do you notice that is different after you get up? So you're saying you wake up on your own?

Daughter: Not necessarily on my own...but he wouldn't be like just rousing me to (false father voice) you've only got five minutes in the shower. I'm so freakin' tired of timed showers! You know I could just have a peaceful morning and I wouldn't have to go to school pissed off.

Mary: Okay. Then you run into your mom, what's different?

Mary appeared to make an attempt at redirecting the daughter, but suddenly moved on. Throughout the remainder of this dialogue, Mary was never able to transition back to what the daughter will be doing differently. This left her focusing on what would be different with her parents when the miracle happens. We reiterate that the problem is not found in how a client responds to the miracle question, but rather if the therapist has the patience and determination to avoid problem solving and direct their clients away from others towards themselves.

Not making the question interactional. Asking the miracle question to an individual can be fairly clear cut. However, when working with couples or families, it is important that the couple or family co-create the miracle. Because the therapist asking the miracle question may recognize that family members have multiple perspectives it can be tempting to do as John did in the following example. "I want to throw a question out for you guys.... Um, I'm going to ask this to Tammy [wife] first and then we'll go back to Leonard [husband])." John then proceeded to ask the miracle question to the wife. He did not bring the husband into the miracle question until questioning moved prematurely to problem solving. In half of the therapy sessions, the therapist clearly did not make the miracle question interactive. 
In another session where the miracle question was asked, the therapist and husband engaged in 14 exchanges before the wife was even asked to participate in the creation of the miracle. During these 14 exchanges there were clear opportunities to invite the wife to join in the conversation. In another example, when working with a couple and their daughter, Mary, the therapist-in-training begins to explore the miracle by focusing on the daughter alone. After rushing too quickly through the client's miracle day, the following discussion takes place:

Mary: Then how does the rest of the night play out for you, before you have to go to sleep again?

Daughter: Dinner and just get my stuff done for the night and be able to watch TV for a change.

Mary: Okay now I'm going to shift over to your parents for a change...

Mary abruptly shifts the discussion without engaging the parents in co-creating the miracle or helping the daughter or system know what to do with the miracle information just discussed. A similar lack of leveraging is evident from other trainees. In many of the sessions that were analyzed, this was a common theme; the therapist worked in isolation with one member of the family and then moved to work in isolation with another person in the room. Only occasionally in these instances did the therapist check in with the other partner or other family members to see how they would respond when their partner responded differently on the day after the miracle.

When a couple or family does not work together in creating the miracle, it becomes segmented and may potentially lose the intervention power that the question is meant to have. If only one person is involved in creating the miracle, it no longer becomes the couple or family miracle, but the individual's miracle. Individual miracles do not allow the couple or family to see that they can work together on creating change, and instead contributes to blaming others for 
change not occurring. A good example of how the miracle is co-created by one student therapist, Angela, is illustrated in the following example:

Wife: He would get up and make me breakfast!

Angela: Okay (nods head up and down)

Husband: I'd get a smile in the morning when I got up... that would be a big difference. Angela: Uh hum. So tell me more about this cooking breakfast (directed to the wife).... Wife: Umm? Maybe he would give me a kiss in the morning. Like as soon as I wake up, not just...or say something like good morning....

Angela: And for you (directed to the husband) you said it would be a smile. Tell me more about that. Would it be a smile from [your wife]

Husband: It would be a hug. Just some kind of recognition in the morning that is positive....

In this example Angela is helping both the husband and the wife to describe the miracle and how their interactions would change with one another. Angela could have ignored the husband and focused on the wife. Instead, we see how much the couple is learning about how they could change their interactions just by having both of them involved in the creation of the miracle.

Ineffective use of scaling questions. Another common mistake we found in the transcripts was ineffective use of scaling questions. Scaling questions are an effective tool that can be used to set goals based on the responses to the miracle question. Therapists ineffectively used scaling questions by focusing on problems and not allowing the client to create the desired solutions on which to focus the scaling questions. Two of the six therapists failed to use scaling questions at 
all as part of the miracle question. The four student-therapists that did use scaling questions neglected to utilize the benefits that they are designed to yield.

John demonstrated how some do not know how to transition into scaling questions, a problem consistent with poor transitioning into the miracle question itself. He abruptly shifted into a scaling question right before the end of the session and only prefaced the question by stating:

John: Um we're almost done here...

John then proceeds to quickly ask the question before ending the session. In this example he appeared only to ask the scaling question as a matter of course rather than to use scaling questions as a means of forwarding the miracle. The client was not able to use the scaling question to help set a goal to work toward, which is one of its primary purposes.

Another major barrier to the effective use of the scaling question is leading the clients. We saw therapists pose scaling questions based on their own interpretation of what should be scaled. Therapists failed to yield to the clients' interpretation of the miracle. For example, Sue said:

Sue: On a scale of one to ten, ten being that, umm, your goals have been met as if the miracle has actually occurred. You're communicating, you're friends, you have a connection, and you both are sharing the roles of taking care of Tim, umm, you're happy. On a scale of, and one being, zero is, sorry. And zero being there's nothing there; you're fighting all the time. Where would you say are right now? Individually? In this example Sue provided the interpretation without input from the clients. Clients were given no opportunity to clarify what the high and low scores could represent, if their interpretations were different. This hindered their ability to help create their own miracle and 
placed the therapist in an expert role, a position not supported by solution-focused therapy. In addition, the question was very confusing and difficult to follow.

One therapist, Peter, pushed the leading of the scaling questions even further by creating the scaling question around a complaint within the miracle. In this example, the client expresses concern over a job and Peter follows it up with:

Peter: Do you feel anxious about getting a job?

Daughter: Yeah. I mean I just don't see how I could go out and get a job. Is anyone going to hire me? Am I actually going to find a job that I like? I don't know where to start; I don't know where to look. I don't know really how to even brush up my resume. Peter: on a scale of one to ten where would you say that your anxiety is right now about this situation?

Daughter: One being...?

Peter: One being that there is no anxiety at all. And ten being that you are stressed to the $\max$.

Daughter: I think I'd probably be like an eight.

Peter: Okay, Okay. What would it look like, um, for you to...what would it take for you to go from an eight to a seven?

Peter fails to focus on the miracle and instead asks a scaling question that relates to some expressed concerns. This problem-focused approach misses the ideals of a solution-focused miracle question. While asking scaling questions as they relate to presenting problems may be appropriate in certain situations, when used in conjunction with the miracle question, scaling questions should be related to the miracle just presented. This likely perpetuated problem talk when the therapist should have been helping them focus on solutions. 
Not all of the student-therapists did poorly in asking scaling questions. However, only one of the six effectively used scaling questions that directly related to the clients' interpreted miracle, and then used the response to the scaling question to help the whole system evaluate how to proceed.

\section{LIMITATIONS AND SUGGESTIONS FOR FUTURE RESEARCH}

A number of important limitations exist. First, the data were taken from role-play videos created for a class assignment. Since therapy is a constructed conversation between therapist and client(s), there are limitations to applying conclusion from this project to a clinical population. Of course, therapists with actual clients may not have responded in the way these "therapists" did, and clients may not have responded in the way these "clients" did. As the "clients" were in the MFT cohort, their responses to the Miracle question as "clients" could have been affected by their familiarity with it. Because the first and sixth author are MFT trainers and have seen these same roadblocks to effective use of the miracle question when we have supervised behind a one-way mirror, we believe that the themes have some validity, but the dialogue may not be representative of the dialogue between actual therapist and clients.

Another limitation is the small size of the data set. The data set contains only six tapes which seemed to represent common roadblocks. Examples of students asking the miracle question without difficulties were not included in the data set. Future projects, using a larger more representative sample of examples of the use of the miracle question, with actual therapistclient dialogues, would enhance our knowledge of the use of the miracle question. Another suggestion for future research would be to examine examples of ways therapists recover from a roadblock discussed here in the use of the miracle question to effectively use solution-focused therapy. 


\section{IMPLICATIONS FOR TRAINING}

Beyond the therapeutic guidelines offered by previous authors throughout this manuscript, several implications for training student therapists to effectively use the miracle question arose from our study. Some suggestions regarding the introduction of the miracle question, framing the question, and follow up are provided. We also make general suggestions about the use of role-plays in increasing student-therapists' comfort with the miracle question. Introducing the miracle question

When introducing the miracle question, student-therapists tended to have trouble managing their timing and anxiety. We suggest that instead of waiting to ask the miracle question until the end of the session, therapists and clients will gain greater value from the miracle question when it is given sufficient time to develop in the session. In our supervision of students using the miracle question, we have suggested that they plan to use the entire hour exploring this question. We further recommend that therapists-in-training be given sufficient time to practice delivering the miracle question to reduce their anxiety. If practice involves a 15 minute role play, the student-therapists may not know what to do after the 15 minutes ends.

\section{Following up the miracle question}

Following up on the miracle question seemed to be one of the most difficult tasks for student-therapists because they did not seem to realize the intricacies in the tasks that are supposed to come after the question itself. The student-therapists' lack of commitment to the miracle question seemed to stem from a lack of trust in the process. We recommend that beginning therapists fully understand the skill and its intent before using it. Focusing on problem 
solving and misuse of scaling are pitfalls that could be avoided by learning about the tenants of SFBT. Also, beginners must remember that in order to direct clients back to themselves rather than on problems and others, therapists must exercise a degree of patience (de Shazer et al., 2007, p. 50) and avoid problem solving. The last area of following up on the miracle question that therapists-in-training failed to do was to make the question relational. A co-created miracle helps families work together to create a more realistic and attainable miracle that has greater potential to benefit all members of a family system. Understanding how the changes from the miracle will reverberate in their relationships, will also help clients bridge the gap between the fantasy of a miracle and the belief that the changes can actually occur. In order to do this well the therapist needs to view tapes of experienced therapists asking the question of couples and families and practice delivering the miracle question to role-played couples and families. Our students in the introductory overview of theories classes had only watched tapes of therapists working with individuals before they attempted to ask the question to couples and families. Therapists should be encouraged to be assertive and vigilant in helping those with less of a voice in the family system contribute to creating the miracle.

\section{Ways to train therapists}

Also, when therapists are taught that the miracle question is a tool for creating hope, their faith in their clients will increase, and their anxiety will decrease as a result. One suggestion for training therapists would be to ask student therapists to make a tape of their first attempts, discuss what they are doing well, and what isn't going well yet, and give students the opportunity to improve. Students are generally able to use the miracle question effectively when they understand the purpose of the question, learn to trust the process, and have time to practice. 
The difficulties that therapists-in-training experienced with framing the miracle question were leading the clients to their miracles and asking the question in a confusing way. It seems obvious that student-therapists should be taught to make the miracle question session clientdriven. However, it might be helpful for student-therapists to learn the common ways that beginning therapists are led astray, such as by defining the miracle for the client. Also, we have learned about framing the miracle question by reading and watching various examples of therapists asking it successfully and unsuccessfully, and student-therapists may also learn from examples.

The therapists-in-training in our sample were able to experience roadblocks to effective use of the miracle question before attempting it with actual clients. We recommend using roleplays in and out of class as a learning tool. In our training, we focus on the strengths of our students and highlight their successes, but we have also found it helpful for them to understand which roadblocks they might be prone to so that they are aware of them before they use the miracle question with clients. The roadblocks that therapists-in-training experienced can also be used as a discussion piece for the ways that the miracle question can fall flat in session. In a process that parallels the miracle question, students who role-play the technique can then gauge their starting point and create goals for how they would like to deliver the miracle question more effectively. 


\section{REFERENCES}

Braun, V. \& Clarke, V. (2006). Using thematic analysis in psychology. Qualitative Research in Psychology, 3, 77-101.

de Shazer, S (1988). Clues: Investigating solutions in brief therapy. New York: Norton.

De Jong, P. \& Berg, I. K. (2002). Interviewing for Solutions. Pacific Grove: Brooks/Cole.

de Shazer, S., Dolan, Y., Korman, H., McCollum, E., Trepper, T. \& I.K. Berg (2007). More than miracles: The State of the Art of Solutions-Focused Brief Therapy (pp. 37-60). New York: Haworth.

Maxwell, J. A. (1996). Qualitative research design: An integrative approach. Thousand Oaks, CA: Sage.

Nau, D. S., \& Shilts, L. (2000). When to use the miracle question: Clues from a qualitative study of four SFBT practitioners. Journal of Systemic Therapies, 19, 129-135.

Shilts, L., Rambo, A., \& Huntley, E. (2003). The collaborative miracle: When to slow down the pace of brief therapy. Journal of Systemic Therapies, 22, 65-73.

Tesch, R. (1990). Qualitative research: Analysis types and software tools. New York: Falmer. 